\title{
Photographic observations on the behaviour of Japanese anchovy Engraulis japonica at night in the sea
}

\author{
Ichiro Aoki, Tadashi Inagaki \\ Ocean Research Institute, University of Tokyo, Nakano, Tokyo 164, Japan
}

\begin{abstract}
Density, spacing and schooling behaviour of Japanese anchovy Engraulis japonica forming scattering layers during the night were investigated at sea by means of underwater stereophotography. The nearest neighbour distance showed very great variation. Mean nearest neighbour distance ranged from $62.5 \mathrm{~cm}(7.8$ body lengths, $\mathrm{BL})$ to $96.2 \mathrm{~cm}(12 \mathrm{BL})$. Anchovy did not swim entirely at random but swam less than $10 \mathrm{BL}$ apart one behind the other on the same plane. The fish exhibited a wide variation of tilt angles with a mean of about $10^{\circ}$ head-up orientation while swimming. Mean densities ranged from 0.25 to 0.87 fish $\mathrm{m}^{-3}$ among stations and depths. It is suggested that this density variation corresponded to differences in ambient temperature, and that the vertical distribution was affected by the depth of the thermocline.
\end{abstract}

\section{INTRODUCTION}

According to various field observations, schooling activity generally breaks down and schools disperse during the night (Woodhead 1966, Blaxter \& Hunter 1982). Aoyama \& Mimoto (1970) observed with an echo sounder that anchovy schools which produced discrete dense echo-traces in daytime diffused into continuous scattering layers at night. On the other hand, Hunter \& Nicholl (1985) held that anchovy continue schooling at night. Under usual light conditions in the sea, however, it appears unlikely that anchovy exhibit the same schooling behaviour at night as they do in the daytime. In order to clear up this confusion, more precise information is needed on individual behaviour and degree of dispersal or aggregation of anchovies at night.

Anchovy schools have been observed at night using bioluminescence (Squire 1978), though more direct observations are required to determine the internal structure of these aggregations. Detailed information on the nocturnal behaviour of anchovy in the sea is not only of ecological interest but also a necessity for the accurate estimation of fish abundance in acoustic surveys.

This paper reports on the density, spacing and schooling behaviour of Japanese anchovy Engraulis japonica, observed by stereo-photography at night in the sea during the spawning period. We use here the term school, as did Radakov (1973) and Blaxter \& Hunter (1982), in a broad sense as a group of fish based on a mutual attraction.

\section{METHODS}

The camera system, used in the same way as in our previous study (Aoki et al. 1986), consists of a pair of cameras, a strobe light and electrical components, all of which were mounted on a frame unit. A full description of the camera system has been given by Aoyama (1984).

During a cruise of the RV 'Tansei Maru' in June 1985 midwater photographic observations were made at 4 stations in Sagami Bay in water depths ranging from 69 to $645 \mathrm{~m}$ (Fig. 1, Table 1). June is the time of the peak spawning season for Japanese anchovy in Sagami Bay (Mitani 1978).

The camera system was hung on a wire from a drifting vessel. Photographs were taken with flash at intervals of about $30 \mathrm{~s}$. A depth-recorder and thermorecorder were attached to the system. During photographic observations, five $400 \mathrm{~W}$ ship lamps were lit and 2 of these lamps situated on the gantry illuminated the sea surface where the camera system was lowered. 


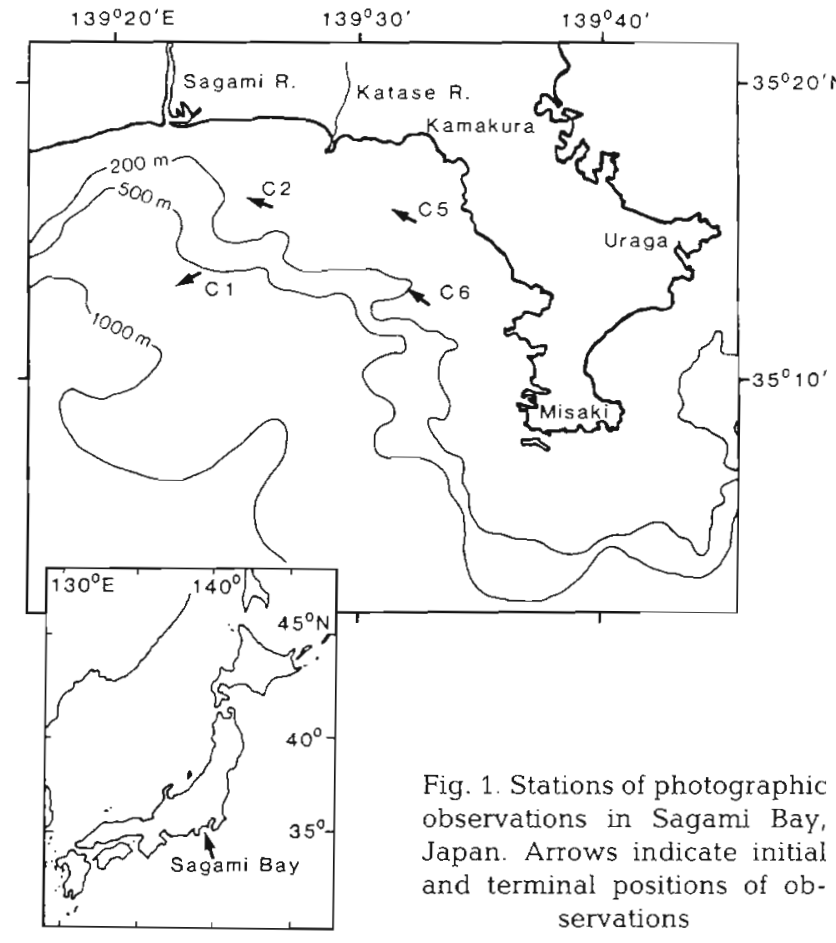

The positions of the snout and caudal-tip point of the body of each fish were measured on each stereo-pair of photographs. When the caudal-tip was obscure due to insufficient illumination, only the position of the snout was measured and its 3-dimensional position was determined, but its body length and direction of body axis were not determined. In the 3-dimensional coordi- nate system, the $\mathrm{X}$-axis is the optical axis of the righthand camera, with the lateral and vertical dimensions represented by the $Y$ and $Z$ axes, respectively. The method for determining the 3-dimensional position of a fish in stereo-photographs has been described by Long \& Aoyama (1985) and Long et al. (1985).

\section{RESULTS}

In this survey area, many vertically elongated echotraces were recorded over a depth range of 10 to $50 \mathrm{~m}$ during the day, with echo-traces of scattering layers observed over the same depth range at night. At the 4 stations, 370 stereo-pairs of photographs were taken: 219 of these showed fish (Table 2). The fish photographed at the offshore station, C1, were not anchovies, but appeared to be round herring Etrumeus teres (Clupeidae), and their photographically determined body lengths ranged from 14 to $19 \mathrm{~cm}$. Anchovy appeared on most of the photographs taken at Stns C2, C5 and C6 (Fig. 2).

Fig. 3 shows the number of fish in each photograph plotted against the distance moved by the drifting ship. At Stn C2, anchovy appeared constantly at depths of 40 and $30 \mathrm{~m}$ over a $600 \mathrm{~m}$ distance. Temperature was about $21^{\circ} \mathrm{C}$ at both depths. Stn $\mathrm{C} 5$, where the camera was positioned at depth $20 \mathrm{~m}$, had a lower fish abundance and slightly lower temperature than Stn C2. At Stn C6, anchovy were more abundant and the temperature was higher at depth $20 \mathrm{~m}$ than at $40 \mathrm{~m}$. Mean numbers of fish in a picture were highest at 30 and

Table 1 Date and time of photographic observation at each station

\begin{tabular}{|c|c|c|c|c|}
\hline Station & $\begin{array}{l}\text { Water depth } \\
\text { (m) }\end{array}$ & Date & $\begin{array}{c}\text { Time (local) } \\
(\mathrm{h})\end{array}$ & Notes \\
\hline $\mathrm{C} 1$ & $585-645$ & 16 Jun 1985 & $21: 22-22: 02$ & \multirow{4}{*}{ 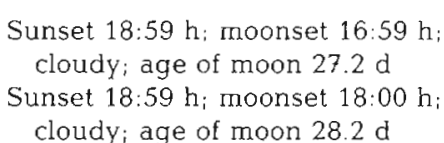 } \\
\hline $\mathrm{C} 2$ & $99-101$ & 16 Jun 1985 & $22: 35-23: 32$ & \\
\hline C5 & $77-73$ & 17 Jun 1985 & $20: 27-21: 02$ & \\
\hline C6 & $69-278$ & 17 Jun 1985 & $22: 00-23: 11$ & \\
\hline
\end{tabular}

Table 2. Summary of the number of fish photographed

\begin{tabular}{|c|c|c|c|c|c|c|}
\hline Station & $\begin{array}{l}\text { Depth of camera } \\
\qquad(\mathrm{m})\end{array}$ & $\begin{array}{c}\text { Mean tempera- } \\
\text { ture }\left({ }^{\circ} \mathrm{C}\right)\end{array}$ & $\begin{array}{l}\text { No. of pictures } \\
\text { taken }\end{array}$ & $\begin{array}{l}\text { No. of pictures } \\
\text { of fish }\end{array}$ & $\begin{array}{l}\text { No. of fish } \\
\text { in pictures }\end{array}$ & $\begin{array}{l}\text { Mean no. of fish } \\
\text { in a picture }\end{array}$ \\
\hline \multirow[t]{2}{*}{$C 1$} & 30 & 21.0 & 49 & 4 & 7 & 0.14 \\
\hline & 70 & 16.7 & 28 & 8 & 13 & 0.46 \\
\hline \multirow[t]{2}{*}{$\mathrm{C} 2$} & 30 & 21.2 & 25 & 22 & 91 & 3.6 \\
\hline & 40 & 21.2 & 64 & 59 & 316 & 4.9 \\
\hline C.5 & 20 & 20.5 & 55 & 25 & 81 & 1.5 \\
\hline \multirow[t]{2}{*}{ C6 } & 20 & 21.0 & 63 & 56 & 285 & 4.5 \\
\hline & 40 & 19.9 & 86 & 45 & 113 & 1.3 \\
\hline
\end{tabular}




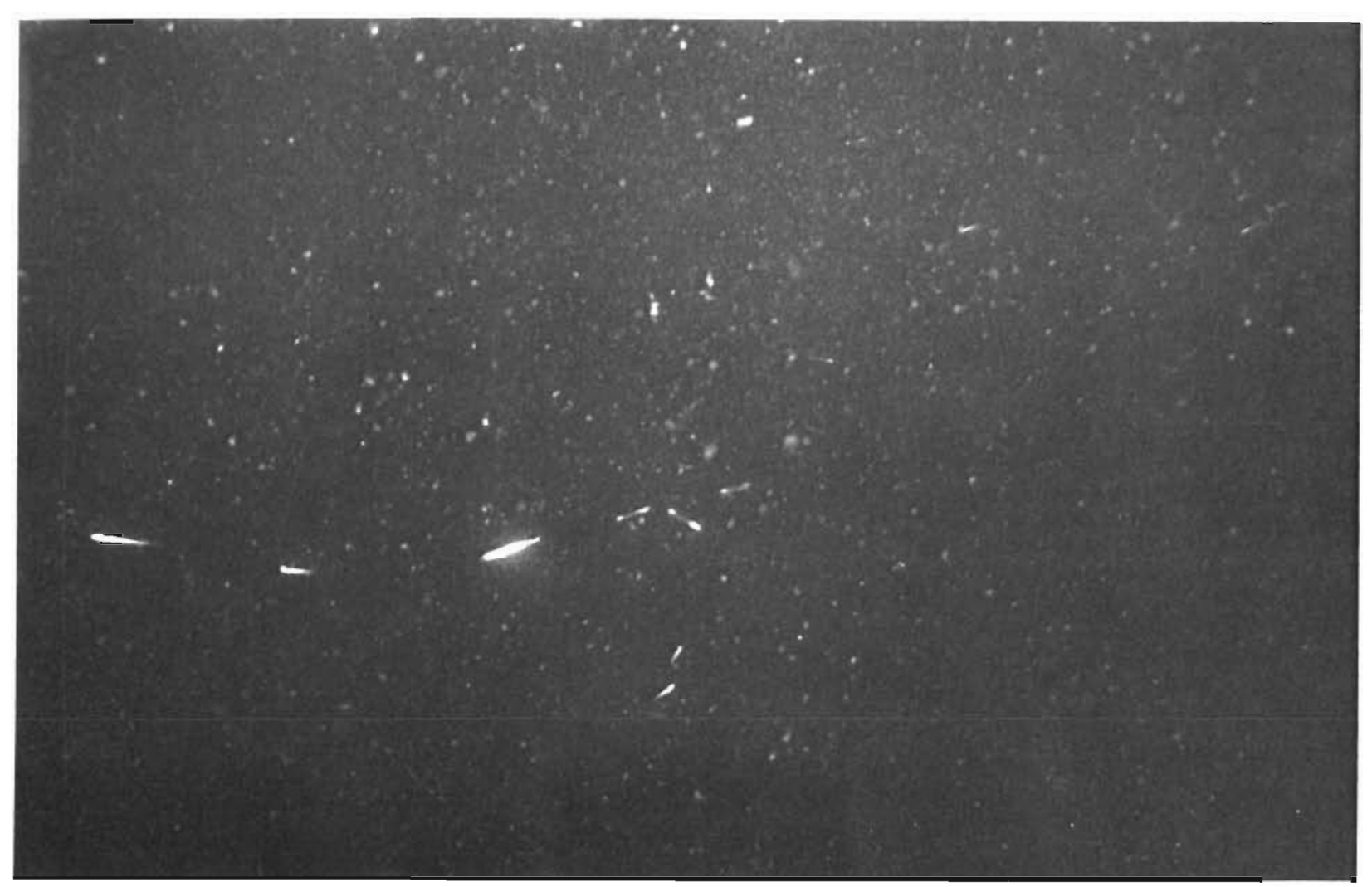

Fig. 2. Engraulis japonica. Japanese anchovy in night-time aggregations. Stn C6, depth $20 \mathrm{~m}$

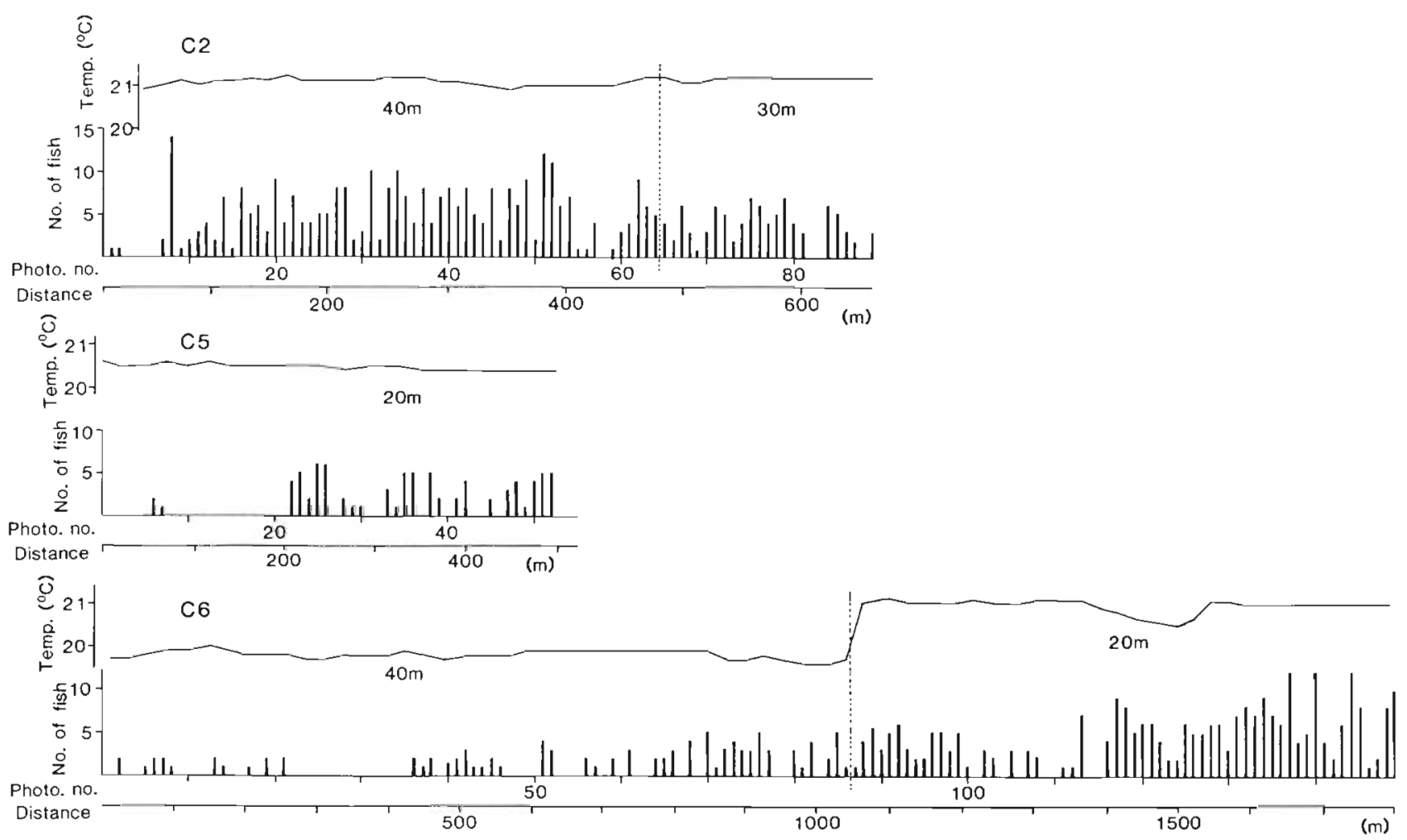

Fig. 3. Engraulis japonica. Number of fish in each photograph and ambient temperature plotted against the distance moved by the drifting ship. Camera depth is indicated 

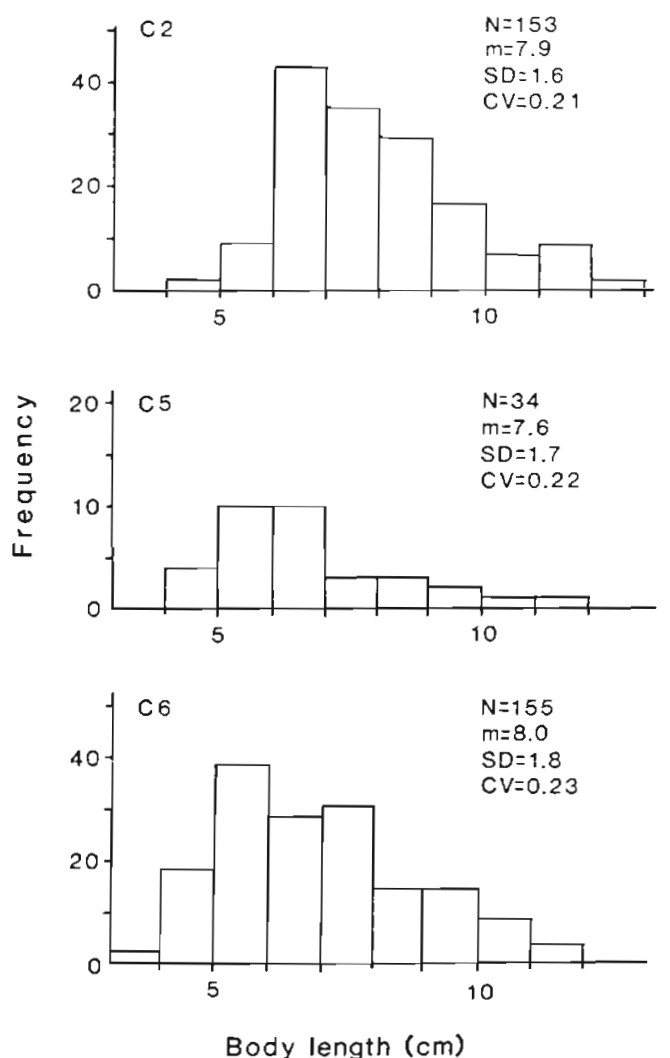

Fig. 4. Engraulis japonica. Frequency distributions of body lengths of the Japanese anchovy observed at each station. N: sample size; m: mean; SD: standard deviation; CV: coefficient of variation

$40 \mathrm{~m}$ at $\operatorname{Stn} \mathrm{C} 2$ and $20 \mathrm{~m}$ at Stn C6, both of which were $1 \mathrm{C}^{\circ}$ warmer than $\mathrm{C} 5(20 \mathrm{~m})$ and $\mathrm{C} 6(40 \mathrm{~m})$ (Table 2$)$. A positive correlation was observed between the mean number of fish in a picture and the mean temperature $(r=0.883, p<0.05)$, but there was no correlation between the mean number of fish and the depth surveyed $(r=0.003, p>0.5$ ). Although other environmental variables were not measured, anchovy might be choosing the $1 \mathrm{C}^{\circ}$ warmer water.

Frequency distributions of photographically determined body lengths are shown in Fig. 4. For each station body lengths ranged approximately from 4 to $12 \mathrm{~cm}$ with a mean of $8 \mathrm{~cm}$ and standard deviation of $2 \mathrm{~cm}$. According to Mitani (1978), the anchovy aggregations consisted of 0 and 1 yr classes.

The tilt angle, defined as the angle between the body axis and the $\mathrm{X}-\mathrm{Y}$ plane, was determined (Fig. 5). No correction was made for inclination of the camera system, even though the $\mathrm{X}-\mathrm{Y}$ plane was not exactly horizontal, since the angle of inclination was within $5^{\circ}$. Tilt angles varied to such an extent that some fish swam with about a $90^{\circ}$ head-up orientation. In addition, tilt angles were generally positive with means of $11.2,12.2$ and $7.3^{\circ}$ head-up orientation for Stns C2, C5 and C6,
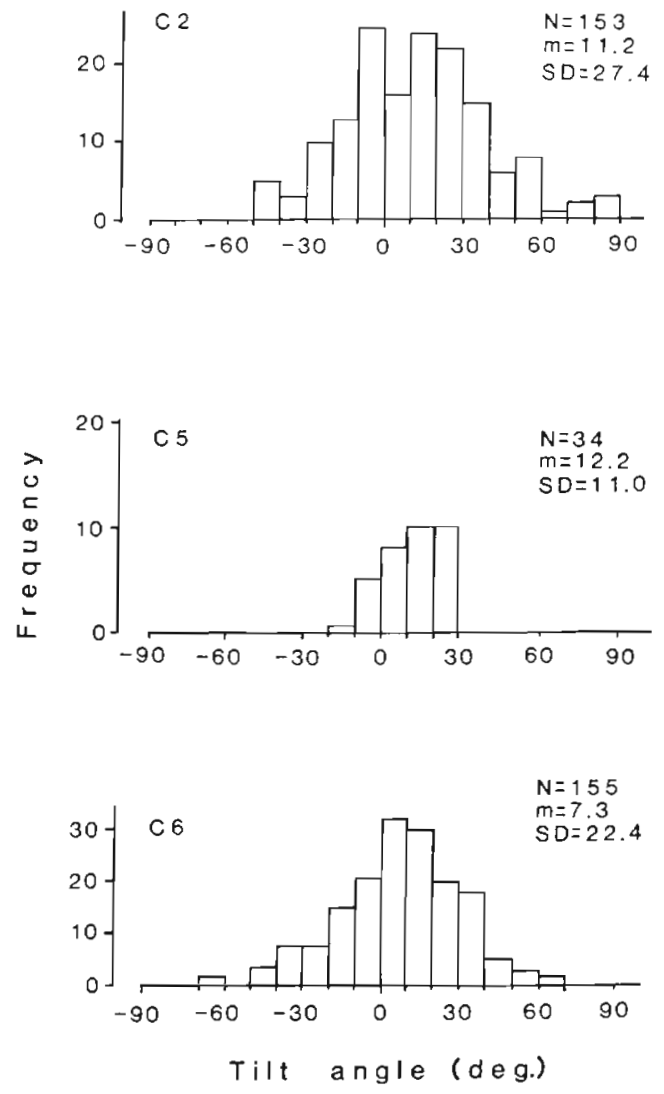

Fig. 5. Engraulis japonica. Frequency distributions of tilt angles of the Japanese anchovy observed at night at each station. $\mathrm{N}$ : sample size; m: mean; SD: standard deviation

respectively. These data on the nocturnal swimming posture of the anchovy agree with those of herring (Buerkle 1983).

Spatial distribution of the anchovy in aggregations is characterized by the distance and direction to nearest neighbour Frequency distributions of nearest neighbour distances are shown in Fig. 6 . The nearest neighbour distance was measured between snouts. In some cases, the apparent nearest neighbour distance may be biased upwards, because it is possible that fish around borders of the visual field have their nearest neighbours outside the visual field.

The nearest neighbour distance showed very great variation. The mode of distribution of nearest neighbour distances varied from the 10 to $20 \mathrm{~cm}$ class (corresponding to 1.25 to 2.5 body lengths, BL, taken as $8 \mathrm{~cm}$ ) to the 50 to $60 \mathrm{~cm}$ class $(6.25$ to $7.5 \mathrm{BL})$ among 5 observation series. The mean nearest neighbour distance ranged from $62.5(7.8 \mathrm{BL})$ to $96.2 \mathrm{~cm}(12 \mathrm{BL})$. More than $50 \%$ of individuals had their nearest neighbours within a range of $80 \mathrm{~cm}(10 \mathrm{BL})$ for each observation series.

Next, we calculated the horizontal bearing and vertical elevation of each fish's nearest neighbour relative 
to its body axis. The frequencies of nearest neighbours at various bearings and elevations are plotted as separate histograms for nearest neighbour distance less than and greater than $80 \mathrm{~cm}$ (Fig. 7). The direction to nearest neighbour was determined from snout to snout. The proportion of volume, compared to a sphere, for each $20^{\circ}$ interval of elevation is also plotted in Fig. 7. When nearest neighbour distance was $\geq 80 \mathrm{~cm}$, the frequency distribution of elevation was close to the volume proportion curve. This indicates that the nearest neighbours were distributed at random in the vertical plane. On the other hand, when nearest neighbour distance was $<80 \mathrm{~cm}$, many more nearest neighbours occurred at elevations of around $0^{\circ}$ than the volume
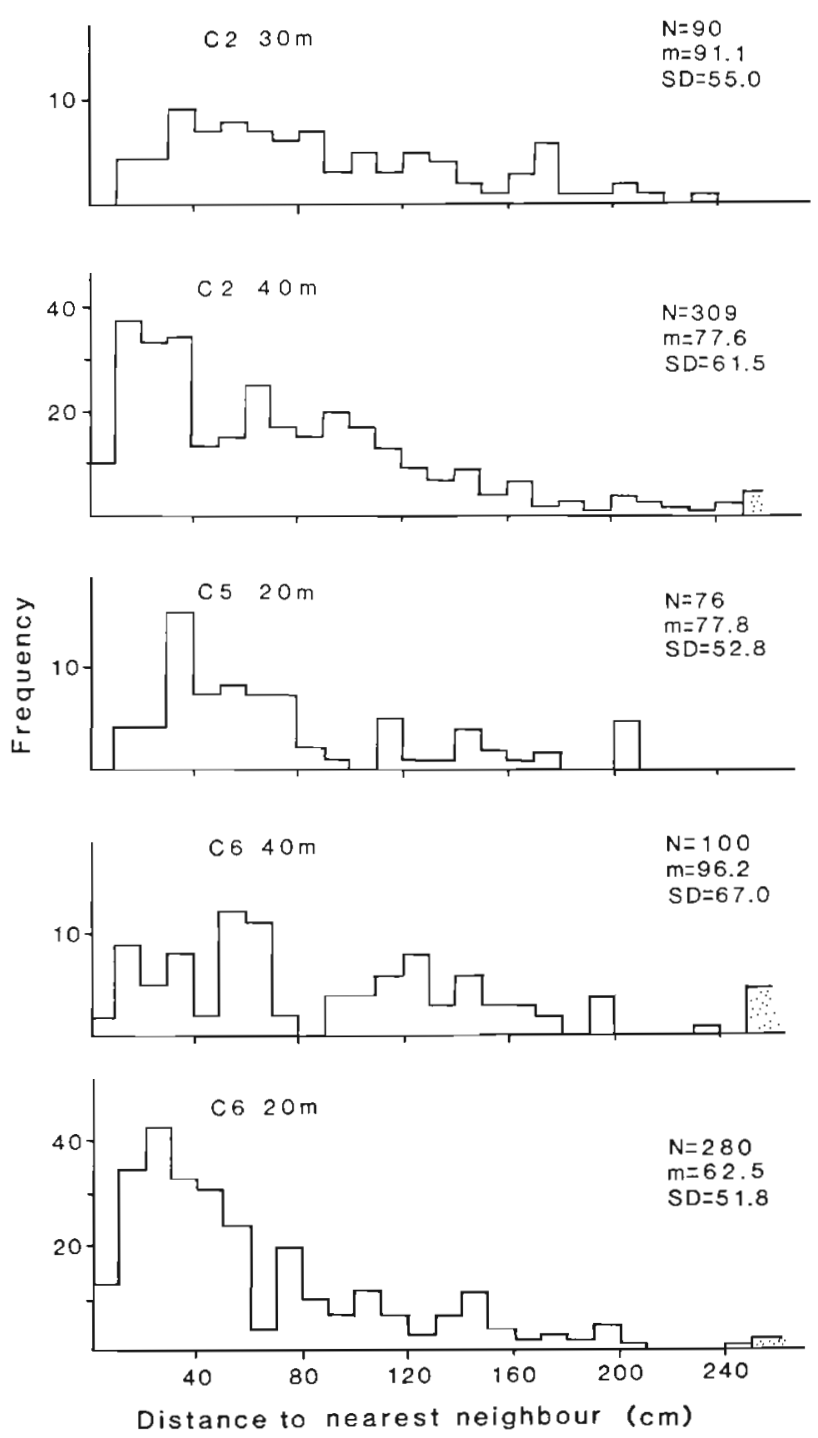

Fig. 6. Engraulis japonica. Frequency distributions of nearest neighbour distances in night-time aggregations of Japanese anchovy. Stippled columns indicate frequencies at distances greater than $250 \mathrm{~cm}$. N: sample size; m: mean; SD: standard deviation proportion, while in the horizontal plane, the bearing of nearest neighbour showed a trend towards 0 and $180^{\circ}$. It is concluded that though the anchovy tended to disperse at night they were not entirely random in their swimming, and that fish which were relatively close to each other swam one behind the other on the same plane.

The density of fish can be calculated from the number of fish photographed and the volume of a quadrangular pyramid determined by the visual angle and range of the camera. However, there is a problem of how to determine the effective range.

Mean density, $D_{i}$, was calculated for each $20 \mathrm{~cm}$ interval of the distance from the camera by the formula $D_{1}=n_{j} /\left(N V_{i}\right)$, where $N$ is the number of photographs taken, $V_{i}$ is the volume of an increment of space from $X_{i}$ to $X_{1}+0.2(\mathrm{~m})$ enveloped by the visual angle of the camera, and $n_{i}$ is the total number of fish in the volume $V$. The $X$-coordinate represents the distance from the camera.

In Fig. 8, $D_{1}$ was plotted against the distance from the camera for each observation series. Each curve of $D_{i}$ first increased and then decreased with a peak at $X=$ 2.6 to $2.8 \mathrm{~m}$. This indicates evasion of fish near the camera and incomplete detection of fish at greater distances due to a reduction of image contrast. Therefore, the fish density will be underestimated if values of $D_{i}$ are simply averaged over the distance. To determine the density exactly, both the detection rate and evasion rate of the fish must be known, but these rates are difficult to measure. In such a case, it is practical to
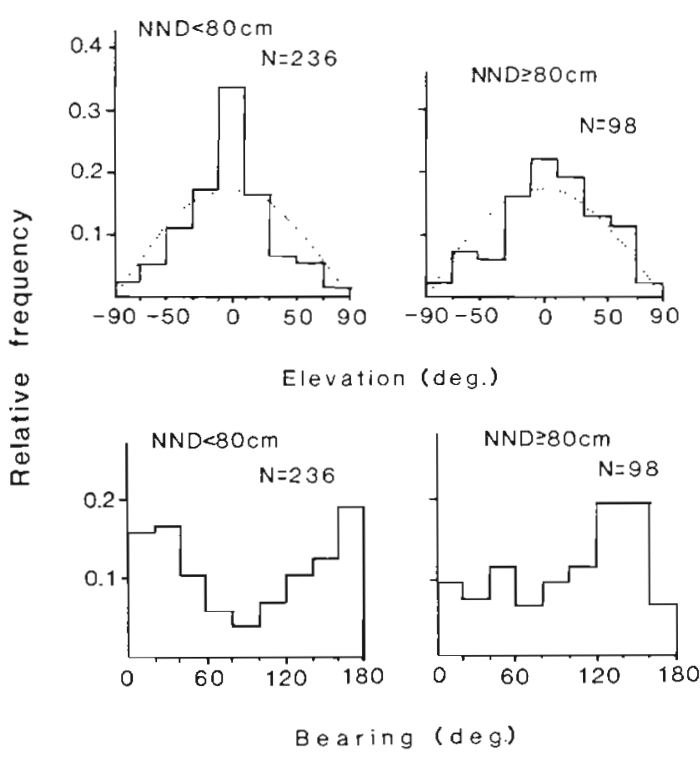

Fig. 7 Engraulis japonica. Frequency distributions of directions to nearest neighbours in night-time aggregations of Japanese anchovy. Histograms are drawn for nearest neighbour distances (NND) less than or greater than $80 \mathrm{~cm}$. Dotted curves in upper figures show proportions of volumes for each $20^{\circ}$ interval of elevation to sphere volume. N: sample size 


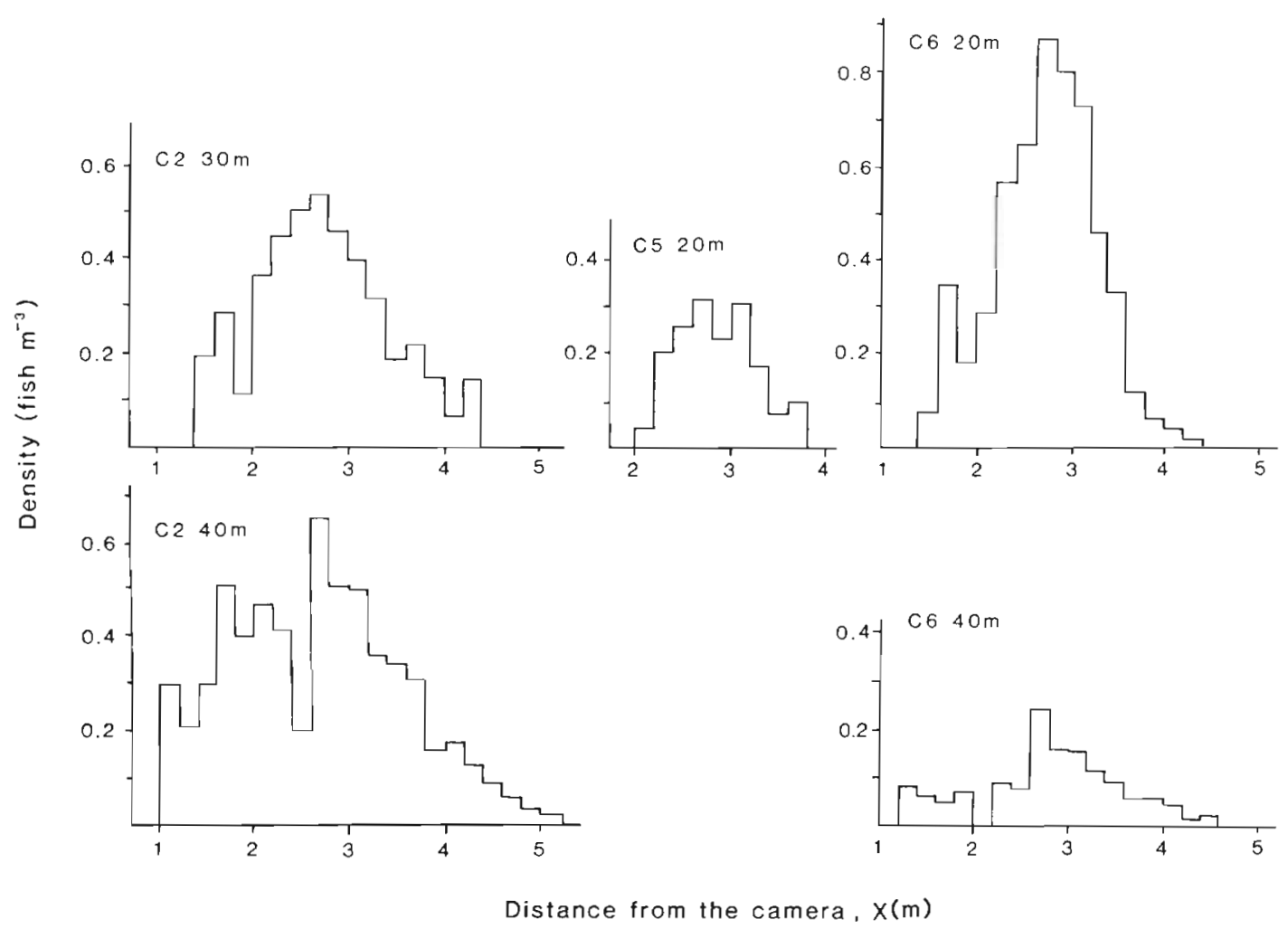

Fig. 8. Engraulis japonica. Mean densities of fish for each $20 \mathrm{~cm}$ interval of the distance from the camera

estimate the density based on some assumption, as seen in the line transect method (Burnham et al. 1980). We here consider this problem simply as follows. The image contrast of the photograph decreases linearly with distance (Matsuike 1984), but it is assumed that the detection rate is constantly 1 (perfect) when the contrast exceeds a certain level or when a fish is within a certain distance, and that below this level it decreases with contrast or distance. It may be realistic to consider that the evasion of fish decreases with the distance from the camera and then does not occur beyond a certain distance (evasion rate $=0$ ). Thus, the maximum value of $D_{i}$ was regarded as a value for the mean density of fish in aggregations. The estimated densities were $0.53,0.68,0.31,0.87$ and 0.25 fish $\mathrm{m}^{-3}$ for respectively 30 and $40 \mathrm{~m}$ depths at Stn C2, Stn C5 (20 m), and 20 and $40 \mathrm{~m}$ depths at C6.

\section{DISCUSSION}

Japanese anchory is a typical schooling species. Aoyama \& Mimoto (1970) found that most Japanese anchovy school were small $(<25$ m horizontal axis,$<20$ $m$ thick) and distributed in a shallow layers (5 to $40 \mathrm{~m}$ depth from the surface), and that the anchovy were arranged in distinct large school groups which consisted of many schools. They also suggested that dis- persal at night and formation in daytime of schools occur within a school group. However, there has been no report on in situ measurement of the internal structure of Japanese anchovy during day or night.

For northern anchovy Engraulis mordax, Mais (1974) reported that the most common school type in daytime was 5 to $30 \mathrm{~m}$ diameter, 4 to $15 \mathrm{~m}$ thick and 0 to $30 \mathrm{~m}$ from the surface. From in situ photographs, Graves (1976) measured the density and spacing within daytime schools of northern anchovy. Analysis of 10 photographs yielded a mean density of 115 fish $\mathrm{m}^{-3}$ and mean nearest neighbour distance of $14.4 \mathrm{~cm}(1.2 \mathrm{BL})$.

The present observations using underwater cameras allowed description of Japanese anchovy aggregations at night. The density and internal structure of aggregations provide a quantitative measure of the school structure.

The estimated mean density of the Japanese anchovy ranged from 0.25 to 0.87 fish $\mathrm{m}^{-3}$ and the mean nearest neighbour distance ranged from $62.5(7.8$ $\mathrm{BL})$ to $96.2 \mathrm{~cm}(12 \mathrm{BL}$ ) among stations and depths. The densities are $1 / 460$ to $1 / 132$ and the nearest neighbour distance in centimeters 4.3 - to 6.7 -fold the mean values for northern anchovy in daytime estimated by Graves (1976). The reciprocal of density is equivalent to the volume per fish, and therefore, its cube root represents the degree of spacing between individuals in one dimension, i.e. the nearest neighbour distance. Accord- 
ing to this calculation, the density, relative to northern anchovy, of $1 / 460$ to $1 / 132$ is converted to a relative nearest neighbour distance 7.7 to 5.1 times that for northern anchovy. This calculated value agrees with the relative nearest neighbour distance (compared directly) of 4.3 to 6.7. From the density of eggs spawned, Smith (1981) estimated the density of adult northern anchovy at night to be $1 / 20$ of that in the daytime. The densities obtained in this study are an order of magnitude smaller. Serebrov (1984) photographed northwestern Atlantic capelin Mallotus villosus schools recorded on the echogram as a hazy layer during the night and determined a mean density of 0.68 fish $\mathrm{m}^{-3}$ and mean nearest neighbour distance of $89 \mathrm{~cm}(5.7 \mathrm{BL})$. The density of the night-time Japanese anchovy aggregations seems comparable to that of the capelin.

The direction to nearest neighbour is another component of the internal structure. Olst \& Hunter (1970) measured bearings of schooling companions in horizontal plane for 6 -fish schools of northern anchovy in a tank, and found that neighbours tended to occur in front of and behind a given fish. Our data obtained for bearing of nearest neighbour within a range of $80 \mathrm{~cm}$ are comparable to these laboratory data. Partridge (1980) reported that minnows in schools of 2 and 3 fish are likely to have their nearest neighbours in front of and behind them in the horizontal plane and at the same level in the vertical plane, but that nearest neighbours occur in all direction in 6-fish schools. The histograms for bearings and elevations of nearest neighbours nearer than $80 \mathrm{~cm}$ are in accordance with those for the 2- and 3-fish schools of minnow.

Whether or not one states on the basis of this feature that schooling continues at night is a problem of terminology. The important fact is that the anchovy, on average, increase the inter-fish distance at night compared to daytime by several times and consequently reduce the density to $1 /$ (a few hundred). However, the fish do not swim entirely at random but, at least at short range, swim with neighbours in an arrangement one can call schooling.

Japanese anchovy spawn during the night before midnight (Nakai et al. 1955). Spawning is likely to have taken place during the time of our observations. No one has yet described the spawning behaviour of anchovy, but pursuit of a female by males is suggested (Hunter \& Nicholl 1985). Mitani (1978) found that in Sagami Bay, Japanese anchovy larger than $8 \mathrm{~cm}$ in body length are capable of spawning. Fish having their nearest neighbours within $80 \mathrm{~cm}$ swam in the same position relative to them, whether or not the fish's body lengths were larger than the sexually mature size of $8 \mathrm{~cm}\left(\chi^{2}\right.$-test, $p>$ 0.5 for elevation, $p>0.25$ for bearing). However, these positional relations may reflect not only schooling behaviour in nocturnal aggregations but also behaviour related to spawning, as in still photographs it is difficult to distinguish pursuit of a female by males from schooling behaviour of a few fish.

Light intensity is a primary factor affecting the maintenance or dispersal of fish schools (Woodhead 1966, Blaxter 1970). In our observations, the ship's lights were the main light source available to the fish as it was a cloudy moonless night (Table 1). The ambient light intensity was not measured, but it was estimated as follows:

Irradiance at a depth of $r \mathrm{~m}, I_{r}$, is expressed by $I_{r}=I_{1}$ $\mathrm{e}^{-K\left(r^{-1}\right)} I^{-2}$, where $I_{1}$ is the irradiance at $1 \mathrm{~m}$ depth and $K$ is the attenuation coefficient. The value of $I_{1}$ was assumed to be in the range 1 to $10 \mu \mathrm{E} \mathrm{m}^{-2} \mathrm{~s}^{-1}$ and that for $\mathrm{K}$ in the range 0.1 to 0.2 from measurements during another cruise in Sagami Bay and from Okami et al. (1978). Using these values the probable ranges of light intensity for the depths surveyed were calculated: $2 \times 10^{-1}$ to $3 \times 10^{-3}$ lux at $20 \mathrm{~m}$ depth, $3 \times 10^{-2}$ to $2 \times 10^{-4}$ lux at $30 \mathrm{~m}$ depth, and $7 \times 10^{-3}$ to $1 \times 10^{-5}$ lux at $40 \mathrm{~m}$ depth (Fig. 9). Although the probable light intensity was lower by 2 orders of magnitude at $40 \mathrm{~m}$ depth than $20 \mathrm{~m}$ depth, fish abundance had no correlation with depth. Therefore, it is considered that the influence of ship's lights, if it existed, was slight in the range of 20 to $40 \mathrm{~m}$ from the surface.

These calculations also indicate that the range of light intensities overlaps Hunter's \& Nicholl's (1985) light intensity threshold for schooling in northern anchovy at 30 and $40 \mathrm{~m}$ depths and exceeds it at $20 \mathrm{~m}$ depth. At $20 \mathrm{~m}$ depth, however, the Japanese anchovy tended to disperse and did not display greater schooling activity than they did in deeper water. The follow-

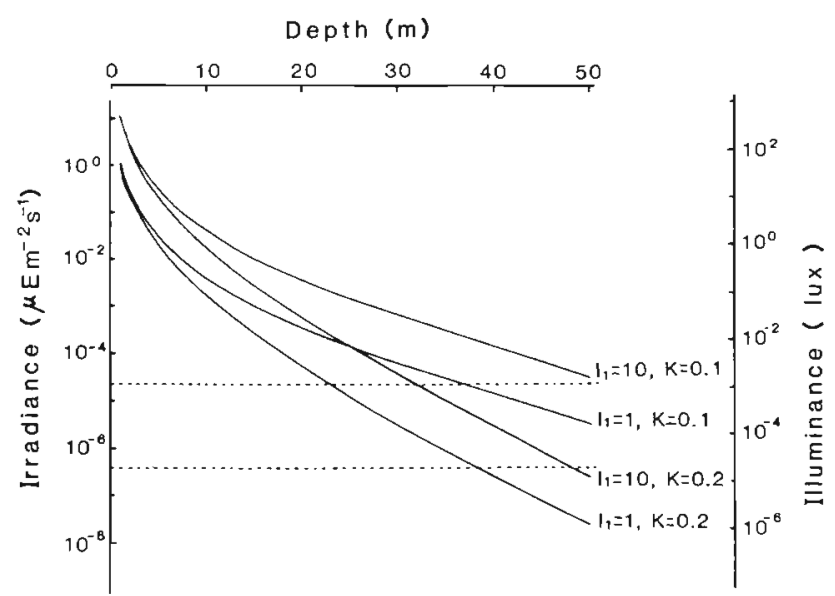

Fig. 9. Calculated vertical profile of light intensity for different light intensities at $1 \mathrm{~m}$ depth $\left(I_{1}\right)$ and attenuation coefficient $(K)$. Broken lines indicate the range of light intensity threshold for schooling in northern anchovy by Hunter \& Nicholl (1985). Units of light intensity are converted according to Strickland (1958) 
ing explanation is more probable than a simple species difference. The anchovy on the photographs appeared to be in visual contact with neighbours over a short range. It has been pointed out that schools often break up even at a light intensity where visual contact among fish is good (Radakov 1973). This may be also the case with our anchovy. By contrast, Glass et al. (1986) obtained, for mackerel, a very low illuminance threshold for schooling, close to that for sight of the fish in well-controlled laboratory experiments. The value obtained by Hunter \& Nicholl (1985) may be such a value.

Blaxter \& Parrish (1965) found on echo-traces that herring tended to disperse as the light decreased below $10^{-1}$ lux. On the other hand, using an underwater camera, Yarvik \& Murav'yev (1982) observed that spawning Baltic herring retained the daytime school structure during the night at a light intensity of $10^{-3}$ to $10^{-4}$ lux. Craig \& Priestley (1960) also photographed herring schools on a spawning ground whose schooling pattern did not vary with the time of day or night. In a few cases, the maintenance of schools has been observed in the sea at a very low light intensity as seen in the laboratory.

Using an underwater camera, Buerkle (1983) observed that herring showed various tilt angles at night. The common wide variation in tilt angle may be ascribed to weak parallel orientation due to the increase in nearest neighbour distance. It is also probable that the dorsal light reaction of pelagic fishes for maintaining posture may weaken at night because of the considerable diminution of brightness of the sea surface.

A knowledge of the accurate target strength of surveyed fish is necessary for acoustic abundance estimation. The target strength varies with the tilt angle of the fish (Nakken \& Olsen 1977), and the degree of dependence on the tilt angle differs among fish species and carrier frequencies (Miyanohana et al. 1983). Target strengths for $100 \mathrm{kHz}$ at $10^{\circ}$ tilt angle are $6 \mathrm{~dB}$ lower for Japanese sardine of $20 \mathrm{~cm}$ body length and $10 \mathrm{~dB}$ lower for spotted mackerel of $20 \mathrm{~cm}$ body length than at $0^{\circ}$ tilt angle (Ishii et al. 1985). The tilt angles observed for the Japanese anchovy show that such measurements are a must before accurate acoustic abundance estimations of Japanese anchovy can be made.

Aoyama \& Mimoto (1970) found differences in vertical distribution of anchovy among survey years and suggested that the anchovy were distributed in shallow layers when the thermocline was shallow and in vertically wide layers when the thermocline was deep. The relationship between fish abundance and ambient temperature shown in this study supports their suggestion. The surface temperature where anchovy were caught in Tokyo Bay and its vicinity ranges from 18 to $23^{\circ} \mathrm{C}$ in June and from 11 to $27^{\circ} \mathrm{C}$ throughout the year (Watanabe \& Inoue 1958). Anchovy can live over such a wide temperature range. However, we found that the temperature difference between 20 and $21^{\circ} \mathrm{C}$ produced a fish density difference of 2 - or 3 -fold. This fact suggests that in a small time scale, relatively low temperatures constitute a barrier to anchovy distribution.

With this kind of observations, possible effects of a camera frame, research vessel and flash are often questioned. Edwards \& Armstrong (1985) used a method of drifting the vessel over schools to minimize the disturbance caused by the vessel, and stated that a camouflage of the camera frame by painting may reduce the effect of the presence of the camera frame. Since our observations were carried out from a drifting vessel at night, when the fish's vision was very limited, it is likely that the vessel and camera caused little disturbance to the fish.

Mackerel react to flash by swimming away from the camera (Edwards \& Armstrong 1985). On the other hand, cod and gobies are not influenced by the flash (Rumohr 1979). Koike \& Matsuike (1987) reported that an intermittent light with blinking frequencies below 0.15 cycles $s^{-1}$ had little effect on jack mackerel. Though the reaction of anchovy to flash is uncertain, if the fish startles at the flash and swims away from the camera, the startled fish is unlikely to be photographed $30 \mathrm{~s}$ later again. It is hoped that further observations will be carried out using slower flash rates and other observation techniques such as high sensitivity TV camera.

Acknowledgements. We are grateful to Mr Isamu Mitani of the Kanagawa Prefectual Fisheries Experimental Station, who gave us useful comments on the Japanese anchovy in Sagami Bay. Thanks are also due to the officers and crew of the RV 'Tansei Maru' of the Ocean Research. Institute for their help and support. We thank 2 referees for criticism.

\section{LITERATURE CITED}

Aoki, I., Inagaki, T., Long, L. V (1986). Measurements of the three-dimensional structure of free-swimming pelagic fish schools in a natural. environment. Bull. Jap. Soc. scient. Fish. 52: 2069-2077

Aoyama, I (1984). An underwater camera system for exploration of deep-sea organisms. In: Marumo, R. (ed.) Marine biological processes. Koseisha Koseikaku Press, Tokyo, p. 330-334

Aoyama, T., Mimoto, K. (1970). The distribution and abundance of Japanese anchovy in Tachibana Bay. In: Report of the investigations of hydrographic conditions and fish schools distribution in Tachibana Bay, Seikai Reg. Fish. Res. Lab., Nagasaki, p. 93-118

Blaxter, J. H. S. (1970). Light, animals, fishes. In: Kinne, $O$. (ed.) Marine ecology, Vol. 1, Part 1. Wiley-Interscience, London, p. 213-320 
Blaxter, J. H. S., Hunter, J. R. (1982). The biology of the clupeoid fishes. Adv. mar Biol. 20: 1-223

Blaxter, J. H. S., Parrish, B. B. (1965). The importance of light in shoaling, avoidance of nets and vertical migration by herring. J. Cons. perm. int. Explor. Mer 30: 40-57

Buerkle, U. (1983). First look at herring distributions with a bottom referencing underwater towed instrumentation vehicle 'Brutiv' FAO Fish. Rep. 300: 125-130

Burnham, K. P., Anderson, D. R., Laake, J. L. (1980). Estimation of density from line transect sampling of biological populations. Wildl. Monogr. 72: 1-202

Craig, R. E., Priestley, R. (1960). Photographic studies of fish populations. Nature, Lond. 188: 333-334

Edwards, J. I., Armstrong, F. (1985). A free fall camera frame for measuring the shoaling parameters of wild free swimming fish. Coun. Meet. int. Coun. Explor. Sea C.M.-ICES B21: 1-4

Glass, C. W., Wardle, C. S., Mojsiewicz, W. R. (1986). A light intensity threshold for schooling in the Atlantic mackerel, Scomber scombrus. J. Fish Biol. 29 (Suppl. A): 71-81

Graves, J. (1976). Photographic method for measuring spacing and density within pelagic fish schools at sea. Fish. Bull. U. S. 75: $230-234$

Hunter, J., Nicholl, R. (1985). Visual threshold for schooling in northern anchovy Engraulis mordax. Fish. Bull. U. S. 83: 235-242

Ishii, K., Furusawa, M., Miyanohana, Y. (1985). A design of fish suspension and tilting system for the fish target strength measurement. Tech. Rep. natl Res. Inst. Fish. Eng., Fishing Boat and Instr. 6: 51-70

Koike, T., Matsuike, K. (1987). Response of a fish school to different blinking frequencies and intensity ratios of intermittent light. Nippon Suisan Gakkaishi 53: 925-932

Long, L. V., Aoyama, T. (1985). Photographic measurement for obtaining the length, aspect and bearing of free-swimming fish from their spatial position. Bull. Jap. Soc. scient. Fish. 51: 191-195

Long, L. V., Aoyama, T., Inagaki, T. (1985). A stereo photographic method for measuring the spatial position of fish. Bull. Jap. Soc. scient. Fish. 51: 183-190

Mais, K. F. (1974). Pelagic fish surveys in the California Current. Calif. Dept. Fish and Game, Fish Bull. 162: 1-79

Matsuike, K. (1984). Marine optics and underwater photography. In: Marumo, R. (ed.) Marine biological processes. Koseisha Koseikaku Press, Tokyo, p. 324-329

Mitani, I. (1978). Japanese anchovy in Kanagawa Prefecture. Kanagawa Prefecture Fisheries Experimental Station Miura
Miyanohana, Y., Ishii, K., Furusawa, M. (1983). Dorsal aspect target strength on five species of fish. Tech. Rep. natl Res. Inst. Fish. Eng., Fishing Boat and Instr, 4: 95-105

Nakai, Z., Usami, S., Hattori, S., Honjo, K., Hayashi, S. (1955). Progress report of the cooperative iwashi resources investigation. Tokai Reg. Fish. Res. Lab., Tokyo

Nakken, O., Olsen, K. (1977). Target strength measurements of fish. Rapp. P.-v. Réun Cons. int. Explor. Mer 170: $52-69$

Okami, N., Kishino, M., Sugihara, S. (1978). Measurements of spectral irradiance in the seas around the Japanese Islands. Tech. Rep. Phys. Oceanogr. Lab., Inst. Phys. and Chem. Res. 2: 1-130

Olst, J. C. van, Hunter, J. R. (1970). Some aspects of the organization of fish schools. J. Fish. Res. Bd Can. 27 : $1225-1238$

Partridge, B. L. (1980). The effect of school size on the structure and dynamics of minnow schools. Anim. Behav. 28: $68-77$

Radakov, D. V. (1973). Schooling in the ecology of fish. John Wiley and Sons, New York. (transl. from Russian by $\mathrm{H}$. Mills)

Rumohr, H. (1979). Automatic camera observations on common demersal fish in the western Baltic. Meeresforschung 27: $198-202$

Serebrov, L. I. (1984). Structure and some peculiarities of group interaction of capelin, Mallotus villosus villosus (Osmeridae). J. Ichthyol. 24: 16-25

Smith, P. E. (1981). Fisheries on coastal pelagic schooling fish. In: Lasker, R. (ed.) Marine fish larvae. University of Washington Press, Seattle, p. 1-31

Squire, J. L., Jr (1978). Northern anchovy school shapes as related to problems in school size estimation. Fish. Bull. U.S. $76: 443-448$

Strickland, J. D. H. (1958). Solar radiation penetrating the ocean. A review of requirements, data and methods of measurement, with particular reference to photosynthetic productivity. J. Fish. Res. Bd Can. 15: 453-493

Watanabe, K., Inoue, M. (1958). On the catch of the anchovy, Engraulis japonica (Houttuyn), in the Tokyo Bay and its vicinity. Bull. Jap. Soc. scient. Fish. 24: 83-86

Woodhead, P. M. J. (1966). The behaviour of fish in relation to light in the sea. Oceanogr. mar. Biol. A. Rev. 4: 337-403

Yarvik, A. R., Murav'yev, V. B. (1982). The school structure of Baltic herring, Clupea harengus membras (Clupeidae), in the trap net zone. J. Ichthyol. 22: 88-96 